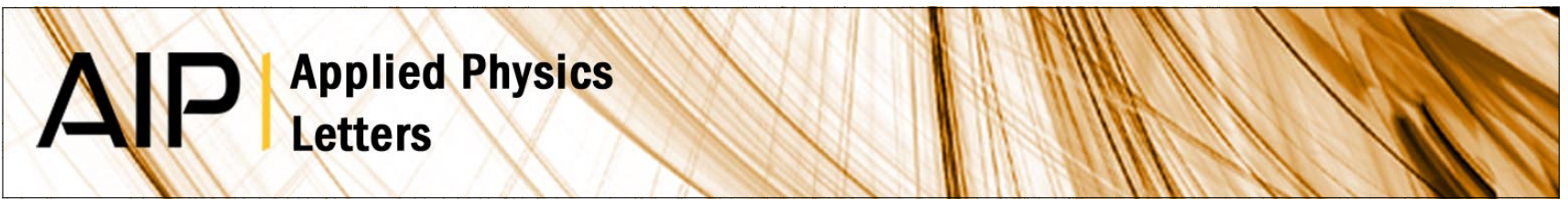

\title{
Ultraviolet laserprojection patterning of polymeric materials for electrochemical gas sensors
}

P. Tejedor and F. Briones

Citation: Appl. Phys. Lett. 64, 936 (1994); doi: 10.1063/1.110950

View online: http://dx.doi.org/10.1063/1.110950

View Table of Contents: http://apl.aip.org/resource/1/APPLAB/v64/i7

Published by the American Institute of Physics.

\section{Related Articles}

Treatment with orthophosphoric acid enhances the thermal stability of the piezoelectricity in low-density polyethylene ferroelectrets

J. Appl. Phys. 111, 124105 (2012)

Electrospinning and optical characterization of organic rubrene nanofibers

J. Appl. Phys. 111, 123504 (2012)

Chain-length dependent growth dynamics of n-alkanes on silica investigated by energy-dispersive $\mathrm{x}$-ray reflectivity in situ and in real-time

J. Chem. Phys. 136, 204709 (2012)

Molecular orientation and anisotropic carrier mobility in poorly soluble polythiophene thin films APL: Org. Electron. Photonics 5, 112 (2012)

Molecular orientation and anisotropic carrier mobility in poorly soluble polythiophene thin films Appl. Phys. Lett. 100, 203305 (2012)

\section{Additional information on Appl. Phys. Lett.}

Journal Homepage: http://apl.aip.org/

Journal Information: http://apl.aip.org/about/about_the_journal

Top downloads: http://apl.aip.org/features/most_downloaded

Information for Authors: http://apl.aip.org/authors

\section{ADVERTISEMENT}

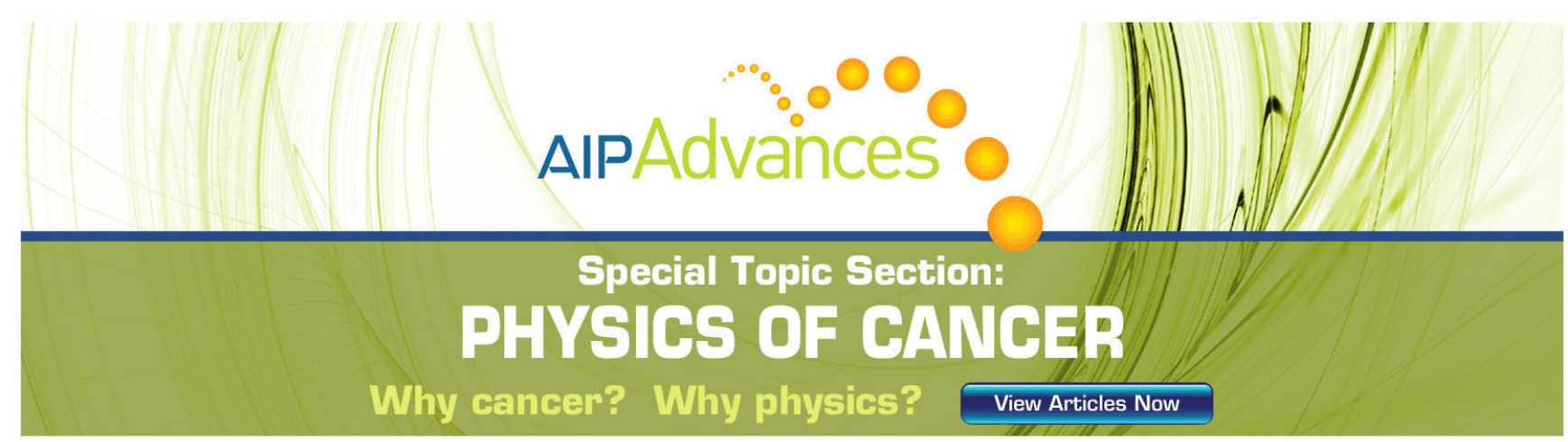




\title{
Ultraviolet laser-projection patterning of polymeric materials for electrochemical gas sensors
}

\author{
P. Tejedor and F. Briones \\ Centro Nacional de Microelectrónica, Serrano, 144-28006 Madrid, Spain
}

(Received 25 June 1993; accepted for publication 24 November 1993)

ArF laser ablation has been successfully applied to maskless pattern by projection lithography of two polymeric materials, polysiloxane and polyHEMA (2-hydroxy-ethyl methacrylate), to be used as gas diffusion membranes in electrochemical gas sensors. Etch rates up to $0.65 \mu \mathrm{m} / \mathrm{s}$ with smooth surface morphology, high edge definition, and a resolution of $\sim 5 \mu \mathrm{m}$ were obtained using laser flucnces between 250 and $400 \mathrm{~mJ} / \mathrm{cm}^{2}$ and repetition rates between 1 and $10 \mathrm{~Hz}$ in air for polyHEMA films and in nitrogen for polysiloxane films.

Elcctrochemical gas detectors based on amperometric measurements made with electrodes covered by polymer membranes have been fabricated and investigated in depth since the introduction of the Clark cell in $1956 .{ }^{1-6}$ Although such detectors have several intrinsic advantages over catalytic and semiconductor gas sensors, such as low operating temperature, lower power consumption, and the possibility of achieving gas selectivity, they have seldom been miniaturized and realized with integrated circuit (IC) compatible methods. Of particular interest is a recently reported type of sensor, the triple-point sensor, ${ }^{2}$ in which a three-dimensional solid-state structure is covered by a gas diffusion polymeric membrane that has to be chemically functionalized to achieve three functions. It should give selectivity for the gases of interest, guarantee a good adhesion to the solid-state structure, and finally, it should have the possibility of photopolymerization. Battiliotti et $a l^{5}$ have recently described the preparation of a new sensitive membrane by a technique compatible with IC technology. The method described by these authors consists in the introduction of amino groups onto the surface of the solid-state device by reacting the surface silanol groups present in $\mathrm{SiO}_{2}$ or $\mathrm{Si}_{3} \mathrm{~N}_{4}$ with suitable functionalized organosilanes such as 3-(2-aminoethyl) aminopropylsiloxane, followed by the coupling of the hydroxyl moiety of 2-hydroxy-ethyl methacrylate (HEMA) with the said amino function, carried out by means of different difunctional condensing agents.

The aim of this work is to evaluate the possible utilization of the excimer laser ablation technique to pattern by projection lithography polysiloxane and polyHEMA films to be used as gas diffusion membranes in electrochemical gas sensors. In the following, the effect of the main process parameters, such as laser fluence, laser repetition rate, and gas ambient on etch rate, surface morphology, resolution, and selectivity with respect to the $\mathrm{SiO}_{2} / \mathrm{Si}$ bottom layer are examined and discussed.

The experimental setup consisted of an ArF excimer laser, an optical system, and an $X-Y$ positioning stage on which the samples were mounted perpendicularly to the laser beam. The ArF Laser (Lambda Physik LPX 200i) could emit 300-mJ pulses of $17-\mathrm{ns}$ duration at $193 \mathrm{~nm}$ and repetition rates up to $50 \mathrm{~Hz}$. The central part of the beam cross section was apertured by a $5 \times 5 \mathrm{~mm}^{2}$ slit, condensed by a $200-\mathrm{mm}$ focal length lens, and imaged through a $\mathrm{Cr}$ on quartz mask by means of a $15 \times$ Schwarzschild microscope objective (NA $=0.28$ ), to give an irradiated area on the sample of $\sim 170$ $\times 440 \mu \mathrm{m}$. The mask pattern consisted of an array of $1-\mathrm{mm}-$ diam holes in a matrix of $0.14-\mathrm{mm}$-wide perpendicular lines. The laser fluence on the samples was varied between 250 and $500 \mathrm{~mJ} / \mathrm{cm}^{2}$ and the repetition rate was kept at $\leqslant 10 \mathrm{~Hz}$. Ablation experiments were performed at room temperature in air or under $\mathrm{N}_{2}$ flow to avoid redeposition of debris. The samples were 50-200 $\mu \mathrm{m}$ thick polyHEMA films deposited on $\mathrm{SiO}_{2} / \mathrm{Si}$ wafers by spin coating. Etch rates were determined by dividing the ablated depth measured with a Taylor-Hobson mechanical stylus by the number of laser pulses emitted during the experiment. The laser fluence was measured using a pyroelectric joulemeter. Etched surface morphology and cross sections were examined in a Hitachi S-800 field emission scanning electron microscope.

PolyHEMA films were cleanly etched by $30-35 \mathrm{~mJ}$ laser pulses at $193 \mathrm{~nm}$, with laser fluences ranging from 250 to $300 \mathrm{~mJ} / \mathrm{cm}^{2}$. Increasing the laser fiuence on the samples resulted in higher etch rates, but above $\sim 303 \mathrm{~mJ} / \mathrm{cm}^{2}$ ablation of the bottom $\mathrm{SiO}_{2}$ layer impeded the obtention of selective etching with respect to this material. The influence of the pulse repetition rate on the ablation process is shown in

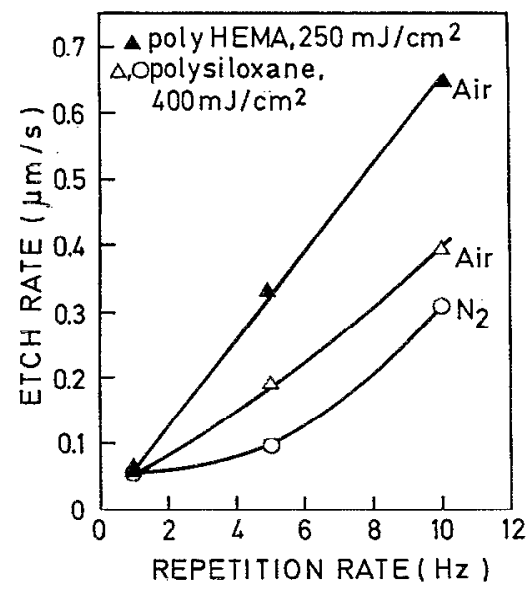

FIG. 1. Etch rate dependence on laser repetition rate for polyHEMA films in air $(\Delta)$, polysiloxane films in air $(\Delta)$, and nitrogen $(O)$, respectively. 


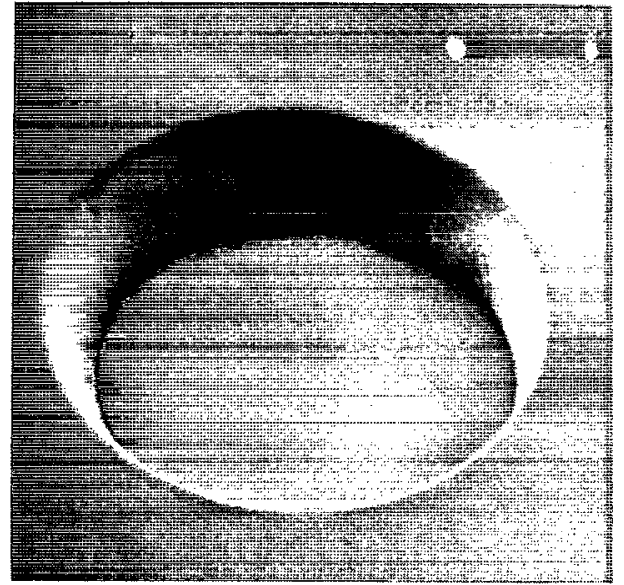

FIG. 2. Etch morphology of a polyHEMA film patterned in air at a laser fluence of $250 \mathrm{~mJ} / \mathrm{cm}^{2}$ and a repetition rate of $5 \mathrm{~Hz}$. (Magnification scale: 15 $\mu \mathrm{m}$.

Fig. 1. The etch rate per second for polyHEMA films irradiated at $250 \mathrm{~mJ} / \mathrm{cm}^{2}$ in air is plotted against the pulse repetition rate. It can be seen in this figure that the etch rate increases with the repetition rate, the former being more than ten times greater at $10 \mathrm{~Hz}$ than at $1 \mathrm{~Hz}$. In consequence, it is worth working at $10 \mathrm{~Hz}$, as no sign of thermal damage of the film surface has been observed at this repetition rate. The scanning electron micrograph shown in Fig. 2 illustrates the etch morphology of a $20-\mu$ m-thick polyHEMA film patterned in air at a laser fluence of $250 \mathrm{~mJ} / \mathrm{cm}^{2}$ and a repetition rate of $5 \mathrm{~Hz}$. The surface morphology around the $\sim 50-\mu \mathrm{m}$ diam etched hole depicted in the figure is very smooth and shows no evidence of thermal damage in the form of cracking or melting of the polymeric material. Moreover, the ablation process does not generate redeposition of material on the surface or the etched features, allowing the obtention of clean and smooth walls and bottom morphologies. The scanning electron microscopy (SEM) photograph of Fig. 3 shows a cross-sectional view of the minimum feature size $(\sim 5 \mu \mathrm{m})$ obtained in polyHEMA films with the projection setup used in our experiments. It should be noted in this micrograph the good edge definition obtained in this material by the laser ablation technique.

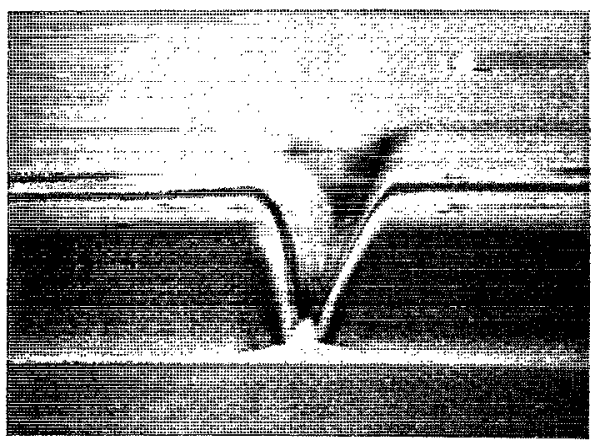

FIG. 3. SEM cross-sectional view of the minimum feature size obtained in a $-20-\mu \mathrm{m}$-thick polyHEMA film by laser projection lithography. (Magniification scale: $20 \mu \mathrm{m}$.)
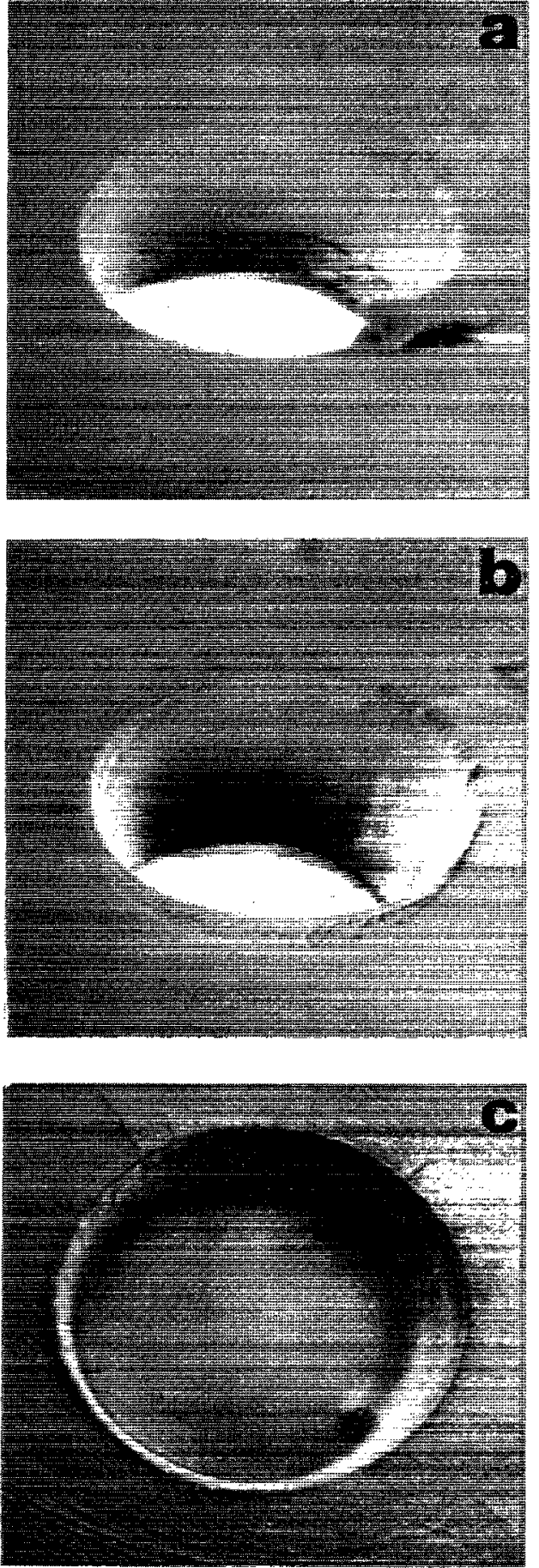

FIG. 4. Effect of laser fluence and gas ambient on polysiloxane etch morphology: (a) $400 \mathrm{~mJ} / \mathrm{cm}^{2}$ and $10 \mathrm{~Hz}$ in air; (b) $400 \mathrm{~mJ} / \mathrm{cm}^{2}$ and $10 \mathrm{~Hz}$ in nitrogen; and (c) $500 \mathrm{~mJ} / \mathrm{cm}^{2}$ and $10 \mathrm{~Hz}$ in nitrogen. (Magnification scale: $20 \mu \mathrm{m}$.)

In contrast with polyHEMA films, that have a strong absorption at the ArF laser wavelength $(193 \mathrm{~nm})$ attributable to the ester groups, ${ }^{7}$ polysiloxane films exhibit lower photosensitivity due to the high silicon content in the polymer backbone, ${ }^{8}$ which results in lower absorption at the same wavelength. In consequence, a laser fluence of at least $\sim 330$ $\mathrm{mJ} / \mathrm{cm}^{2}$ is required to induce photoablation of this polymer. At a laser fluence of $400 \mathrm{~mJ} / \mathrm{cm}^{2}$, for instance, the observed 
etch rates of polysiloxane films in air are considerably lower than those for polyHEMA samples at $250 \mathrm{~mJ} / \mathrm{cm}^{2}$, although the etch rate dependence on the repetition rate follows a similar trend, as depicted in Fig. 1. The utilization of a nitrogen flow over the polysiloxane samples during the ablation experiments tends to decrease the etch rate, but it helps removing the ablated material that redeposits in the etched hole and on the nonirradiated surface. When the laser fluence is increased above $500 \mathrm{~mJ} / \mathrm{cm}^{2}$, we have observed a morphological transition from smoothly to roughly etched surfaces accompanied by signs of thermal damage. The SEM photographs shown in Fig. 4 illustrate the effect of laser fluence and gas ambient on polysiloxane etch morphology. Figures 4(a) and 4(b) correspond to a polysiloxane film patterned at a laser fluence of $400 \mathrm{~mJ} / \mathrm{cm}^{2}$ and a repetition rate of $10 \mathrm{~Hz}$ in air and nitrogen, respectively. It is evident from these micrographs that the surface morphology using this laser fluence is very smooth and shows no indication of thermal damage. The edge definition of the $\sim 65-\mu \mathrm{m}$-diam etched holes is not as good as the one observed in polyHEMA films, but this could be a consequence of a nonperfectly focused laser beam. On the other hand, the utilization of a nitrogen flow over the polysiloxane sample during the laser ablation experiments is necessary in order to avoid the redeposition of ablated material and obtain clean and smooth etched walls and bottom morphologies. The SEM micrograph showed in Fig. 4(c) corresponds to the same polysiloxane film patterned in nitrogen using a laser fluence of $500 \mathrm{~mJ} / \mathrm{cm}^{2}$ and a repetition rate of $10 \mathrm{~Hz}$. As it was mentioned above, at this high laser fluence, the polymeric film surface evidences signs of thermal damage such as cracks and rough morphology as well as melting around the cdge of the etched hole. Therefore, it is of critical importance to operate at laser fluences just sufficient or slightly above the threshold to start photoablation of the polymer in order to obtain acceptable etch morphologies using the laser ablation technique.

Finally, given that the laser fluence threshold for photoablation of polysiloxane is approximately $30 \mathrm{~mJ} / \mathrm{cm}^{2}$ greater than that for $\mathrm{SiO}_{2}$; it was not possible to obtain selective etching of the polymeric film with respect to the $\mathrm{SiO}_{2}$ bottom layer. This is a technological issue that needs to be addressed in order to apply the laser ablation technique to the patterning of polysiloxane films to gas sensors fabrication. The use of an in situ optical technique that will allow for the accurate determination of the polymer etch end point will probably be most useful in solving this problem.

The authors wish to thank P. van der Wal for supplying the polymer samples and J. D. Gómez for his valuable technical assistance in scanning electron microscopy. This work was partially supported by the EC under the ESPRIT Project No. 6374 (Materials, Methods, and Microtechnologies for Selective Gas Sensing).

${ }^{1}$ L. C. Clark, Trans. Am. Soc. Artif. Intern. Organs 2, 41 (1956).

${ }^{2}$ S. Gernet, M. Koudelka, and N. F. de Rooij, Sensors and Actuators 18, 58 (1989).

${ }^{3}$ F. Maseeh, M. J. Tierney, W. S. Chu, J. Joseph, H. L. Llim, and T. Otogawa, in Proceedings of the 1991 International Conference on Solid-State Sensors and Actuators Transducers '91 (IEEE, New York, 1991), pp. 359-363.

${ }^{4}$ P. van der Wal, E. J. R. Sudholter, and D. N. Reinhoudt, Anal. Chim. Acta 231, 41 (1990).

${ }^{5}$ M. Battilioti, R. Colilli, I. Giannini, and M. Giongo, Sensors and Actuators 17, 209 (1989).

${ }^{6} \mathrm{~L}$. De Anglis and N. Minnaja, Sensors and Actuators B3, 197 (1991).

${ }^{7}$ G. M. Davis and M. C. Gower, J. Appl. Phys. 61, 2090 (1987).

${ }^{8}$ D. S. Soane and Z. Martynenko, Polymers in Microelectronics: Fundamentals and Applications (Elsevier, Amsterdam, 1989), p. 137. 